\title{
Four explicit formulae for friction factor calculations in pipe flow
}

\author{
V. E. M. G. Diniz ${ }^{1}$ \& P. A. Souza ${ }^{2}$ \\ ${ }^{1}$ Hydraylic Engineering Consultant, Brazil \\ ${ }^{2}$ Department of Hydraulic and Sanitary Engineering of Polytechnic \\ School, São Paulo University, Brazil
}

\begin{abstract}
This paper presents four explicit formulae to calculate the friction factor for all flow regimes present at Moody diagram without iterations, including the critical zone, for four different problems. The first formula is used to calculate the head losses of pipes given its discharges, lengths, diameters, absolute roughness, the kinematic viscosity of the fluid that flows in the pipes and the gravity acceleration. The second formula is used to calculate the discharges of pipes given its head losses, lengths, diameters, absolute roughness, the kinematic viscosity of the fluid that flows in the pipes and the gravity acceleration. The third formula is used to calculate the diameters of pipes given its discharges, lengths, head losses, absolute roughness, the kinematic viscosity of the fluid that flows in the pipes and the gravity acceleration. The fourth formula is used to calculate the diameters of pipes given its lengths, head losses, absolute roughness, the kinematic viscosity of the fluid that flows in the pipes, the fluid velocities in the pipes and the gravity acceleration. The calculated friction factors are used to calculate the discharges, head losses and diameters of pipes for the steady state and for the extended period state. A case study is presented where it was possible to apply the first two formulae to calculate the friction factors for the steady state in a water main with nine pipes. The results show that the two applied formulae are working well because the calculated pressure heads of some nodes of the water main were compared to the pressure heads gauged in situ on the same nodes of the water main and the results were close.
\end{abstract}

Keywords: friction factor calculation, explicit formulae, Moody diagram, four different problems, steady state, case study. 


\section{Introduction}

When a fluid flows from one point to another inside a pipe, there will always be a head loss (liquid or gas). This head loss is caused by the friction of the fluid with the inner surface of the pipe wall and by turbulences of the fluid flow. So, the greater the roughness of the pipe wall or the more viscous the fluid, the greater the head loss.

In order to establish laws that may govern the head losses in conduits, research and studies have been carried out for around two centuries. Currently the most precise and universally used expression for analysis of flow in pipes, which was proposed in 1845, is the well-known Darcy-Weisbach equation. Nevertheless, a safe way to determine the friction factor (f) was not found early. The determination of the friction factor is a difficult problem to solve; for the steady state as for the transient state. Only in 1939, almost 100 years later, a law was definitely established to determine the friction factor for the permanent regime, through the Colebrook-White equation [1].

The modeling of the friction factor in a transient flow is generally accomplished either considering it equal to the friction factor for the steady state that occurs at each time step, or considering it constant and equal to the friction factor for the initial steady state, but it is not taken into account that during the transient flow, the velocity profile changes at every time step, even occurring the reverse flow. During a transient it is possible to occur a velocity profile that generates no discharge with a shear stress different from zero on the pipe wall. The use of a constant friction factor can lead to an error of prediction in the study of the phenomenon of liquid column separation during the passage of reflected waves (Lima [2]).

The Colebrook-White equation has been considered as the most precise law of resistance to flow and it has been used as a referential standard, but in spite of this and the whole theoretical fundamentalism and base associated to it, it has a feature which is inconvenient to some people: It is implicit in relation to the friction factor, that is, the unknown $\mathrm{f}$ is present on both sides of the equation, without the possibility of being isolated from the other quantities presented in the equation. Its resolution requires an iterative process. It has given rise to many researchers, almost all over the world, to strive themselves in finding explicit equations, which could be used as alternatives to the Colebrook-White equation, to calculate the friction factor. Some more compact and simple, easier to be memorized, but with large deviations, others less compact and complex, more difficult to be memorized, but with minor deviations and some others matching simplicity and accuracy, with errors well reduced, in relation to the friction factor calculated with the Colebrook-White equation [1].

This paper presents four explicit formulae to calculate the friction factor for four different problems. These formulae calculate the friction factors for all flow regimes present at Moody diagram without iterations, including the critical zone, where the Reynolds number (Re) varies from 2500 to 4000. 


\section{Literature review}

Kamand [3] presented mathematical and graphical methods to relate the friction factors of three widely used pipe friction equations and to determine the magnitude of the differences in calculated head losses. Friction factors were developed to be used with the Hazen-Williams and the Manning equations for PVC and cast-iron pipes that give similar calculated head losses to those of the Darcy-Weisbach equation. The friction factors developed should provide satisfactory results unless other values based on actual field or lab measurements or on practical experience are available.

Von Bernuth and Wilson [4] collected friction loss data for three small diameter plastic pipe sections. Data analysis confirmed that the Blasius equation is a very accurate predictor of the friction factor when Reynolds numbers are less than $10^{5}$. A combination of the Blasius and Colebrook-White equations was proposed as a convenient and accurate head loss prediction equation. The combination equation is dimensionally homogeneous, correctable for viscosity changes and accurate for small diameter plastic pipe as it is normally used. It is conveniently written in flow rate, pipe diameter and pipe length terms.

Sonnad and Goudar [5] analyzed the general applicability of a recent explicit expression of the Colebrook-White equation for turbulent flow friction factor calculation. This explicit expression, which is based on the Lambert $W$ function, contains an exponential term which imposes restrictions on its use. These constraints were expressed in terms of the pipe roughness and fluid Reynolds number for both single and double precision calculations, respectively. A mathematical relationship between the Reynolds number and the pipe roughness at this limiting condition was also presented. Before computing friction factors using the explicit Colebrook-White equation, a quick check must be performed to see if the desired combination of pipe roughness and fluid Reynolds number values satisfies the applicable constraint mentioned above.

McKeon, Zagarola and Smits [6] examined power laws, classical logarithmic and generalized logarithmic friction factor relationships using high-Reynoldsnumber pipe-flow data in the range $31 \times 10^{3} \leq R e \leq 35 \times 10^{6}$. The constants of Prandtl's 'universal' friction factor relationship were shown to be accurate over only a limited Reynolds-number range and unsuitable for extrapolation to high Reynolds numbers. New constants, based on a logarithmic overlap in the mean velocity, were found to represent the high-Reynolds-number data to within $0.5 \%$, and yield a value for the von Kármán constant that is consistent with the mean velocity profiles themselves. The use of a generalized logarithmic law in the mean velocity was also examined. A general friction factor relationship was proposed that predicts all the data to within $1.4 \%$ and agrees with the Blasius relationship for low Reynolds numbers to within $2.0 \%$.

Yoo and Singh [7] proposed two methods for the computation of friction factors of commercial pipes in an explicit way. The first method computes the mean zero velocity point (MZVP) and the other directly computes the mean friction factor (MFF). The MFF method is preferred because it covers all flow ranges, including laminar flow. Both MFF and MZVP methods consider two 
parts of a wall with different roughness heights: One part is rough and the other is smooth. The materials of the pipes tested were galvanized iron, wrought iron, cast iron, concrete, riveted steel, and PVC. The analysis showed that both the roughness height and the relative contribution of the rough part are strongly dependent on the pipe diameter as well as to the type of pipe. The MFF method gave an average error of less than 3\%, whereas the traditional Colebrook-White equation gave an average error of more than $11 \%$ when compared with Colebrook's data.

Sonnad and Goudar [8] presented a mathematically equivalent representation of the Colebrook-White equation to compute friction factor for turbulent flow in rough pipes. This new form is simple; it is explicit in $\mathrm{f}$ (friction factor), no iterative calculations are necessary to estimate $f$ and it is well suited for accurate friction factor estimation. A limiting case of this equation provided friction factor estimates with a maximum absolute error of 0.029 and a maximum percentage error of $1 \%$ over the entire range of pipe roughness and fluid Reynolds number values encountered in practice. The accuracy of this new equation was better than the best currently available non-iterative approximation of the Colebrook-White equation at the expense of a $30 \%$ increase in computational effort. This new representation obviates the use of empirical methods, an approach that has been widely used to date.

Cheng [9] concerned variations of the friction factor in the two transitional regimes, one between laminar and turbulent flows and the other between fully smooth and fully rough turbulent flows. A useful interpolation function was proposed to derive a single explicit formula for computing the friction factor in all flow regimes. The resulted explicit formula represents well the experimental data by Nikuradse for pipes roughened by well-sorted sand grains, in comparison with other implicit formulas available in the literature. Certain modifications were also made for applying the obtained friction factor formula in twodimensional open-channel flows for all flow regimes. It should be mentioned that the results presented were largely based on Nikuradse's study, and thus their applications could be limited.

\section{Method}

It will be presented four explicit formulae to calculate the friction factor for four different problems without iterations. The calculated friction factors are used to calculate the discharges, head losses and diameters of pipes for the steady state and for the extended period state.

To develop the four formulae to calculate the friction factor, the authors used the two following equations:

$$
\begin{gathered}
(f)^{-1 / 2}=-2 \log \left[2,51(\operatorname{Re} \sqrt{f})^{-1}\right] \\
(f)^{-1 / 2}=-2 \log \left[a(\operatorname{Re})^{-b}\right]
\end{gathered}
$$

Eqn. (1) is the Colebrook-White equation for the smooth turbulent flow and eqn. (2) was developed by Konakov apud Nekrasov [10]. From these equations, 
it was made several curve fittings and mathematical operations to develop the four formulae to calculate the friction factor explicitly.

Souza [11] developed four block diagrams (shown ahead) to calculate the friction factor explicitly for four different problems. The block diagrams show that it is possible to calculate the friction factor for all flow regimes present at Moody diagram without iterations, except for the critical zone. To overcome this problem, Souza [11] used Hermite polynomials to calculate the friction factor for the critical zone. Next, the four block diagrams for the four problems are going to be presented. This paper will not detail the use of Hermite polynomials because this is not its purpose.

\subsection{Block diagram for problem 1}

The first formula is used to calculate the head losses of pipes given its discharges, lengths, diameters, absolute roughness, the kinematic viscosity of the fluid that flows in the pipes and the gravity acceleration.

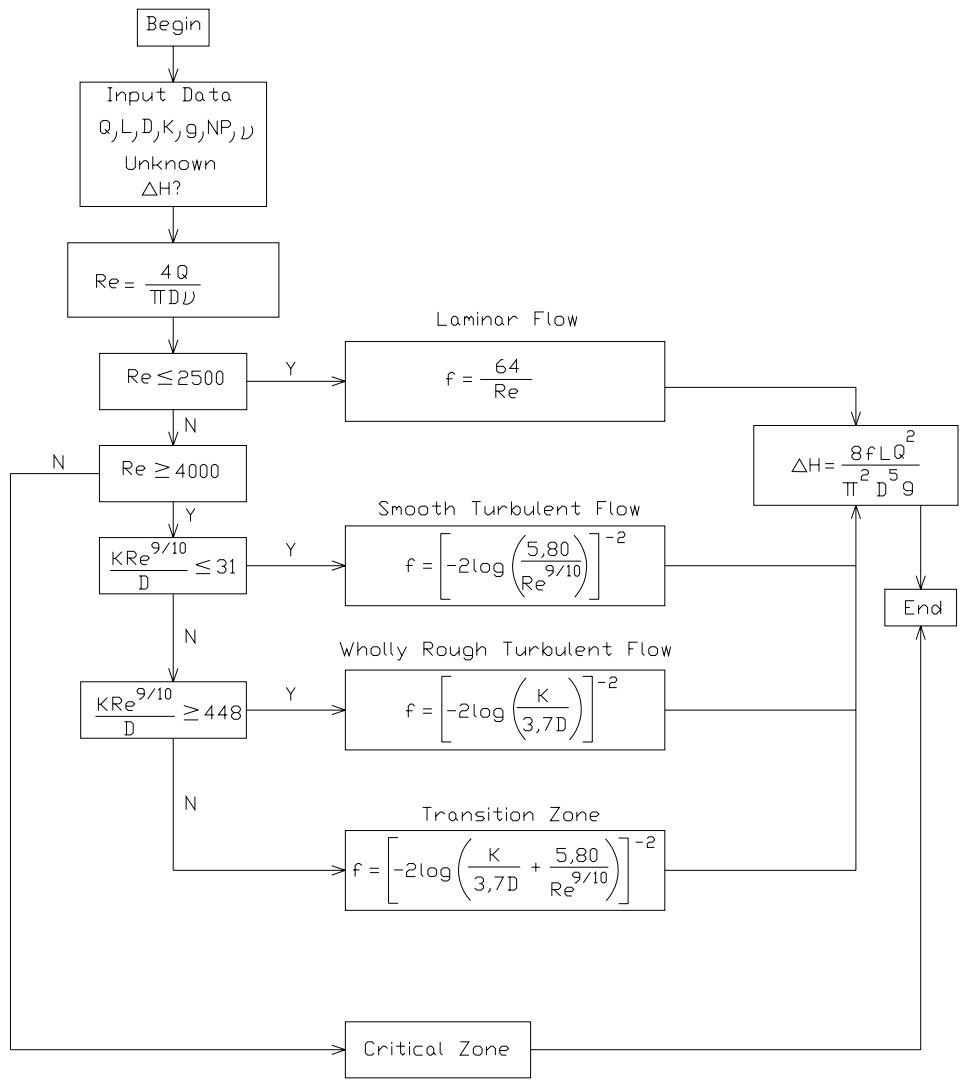

Figure 1: $\quad$ Block diagram for problem 1. 
To calculate the head losses in fig. 1, it is proposed to use the Swamee-Jain equation to calculate the friction factors for all flow regimes at Moody diagram, including the critical zone, instead of using the equations for " $\mathrm{f}$ " in fig. 1.

$$
f=\left\{\left(\frac{64}{R e}\right)^{8}+9,5\left[\ln \left(\frac{k}{3,7 D}+\frac{5,80}{R e^{9 / 10}}\right)-\left(\frac{2500}{R e}\right)^{6}\right]^{-16}\right\}^{0,125}
$$

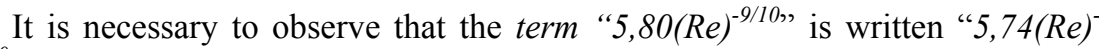
$9 / 10$ " in the original Swamee-Jain equation. Based on a curve fitting, the authors

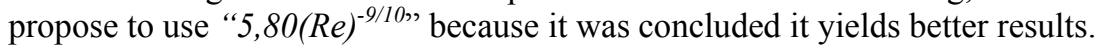

\subsection{Block diagram for problem 2}

The second formula is used to calculate the discharges of pipes given its head losses, lengths, diameters, absolute roughness, the kinematic viscosity of the fluid that flows in the pipes and the gravity acceleration.

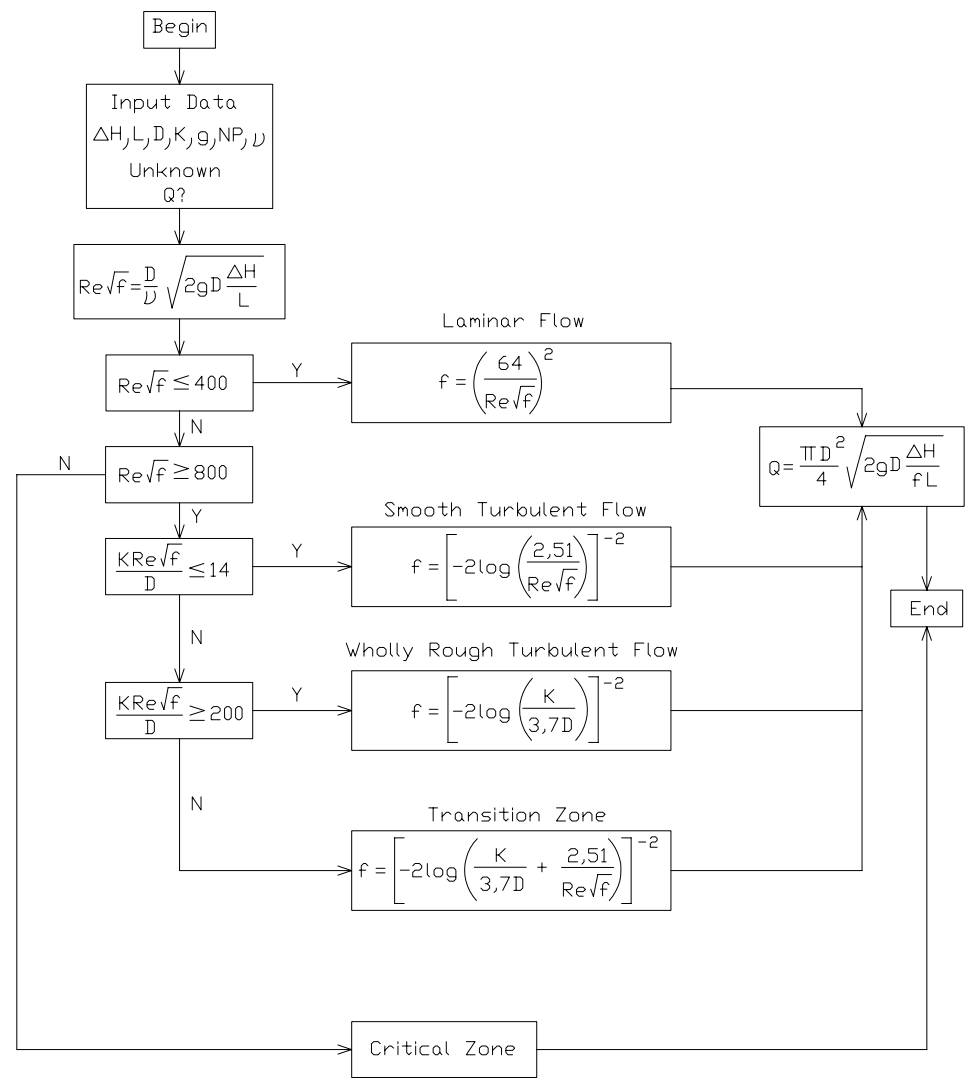

Figure 2: $\quad$ Block diagram for problem 2. 
To calculate the discharges in fig. 2, it is proposed to use the following equation to calculate the friction factors for all flow regimes at Moody diagram, including the critical zone, instead of using the equations for " $\mathrm{f}$ " in fig. 2. It is important to note that the term "Ref $f^{d / 2}$ " is defined in fig. 2.

$$
f=\left\{\left(\frac{64}{\operatorname{Re} \sqrt{f}}\right)^{16}+9,5\left[\ln \left(\frac{k}{3,7 D}+\frac{2,51}{\operatorname{Re} \sqrt{f}}\right)-\left(\frac{400}{\operatorname{Re} \sqrt{f}}\right)^{6}\right]^{-16}\right\}^{0,125}
$$

\subsection{Block diagram for problem 3}

The third formula is used to calculate the diameters of pipes given its discharges, lengths, head losses, absolute roughness, the kinematic viscosity of the fluid that flows in the pipes and the gravity acceleration.

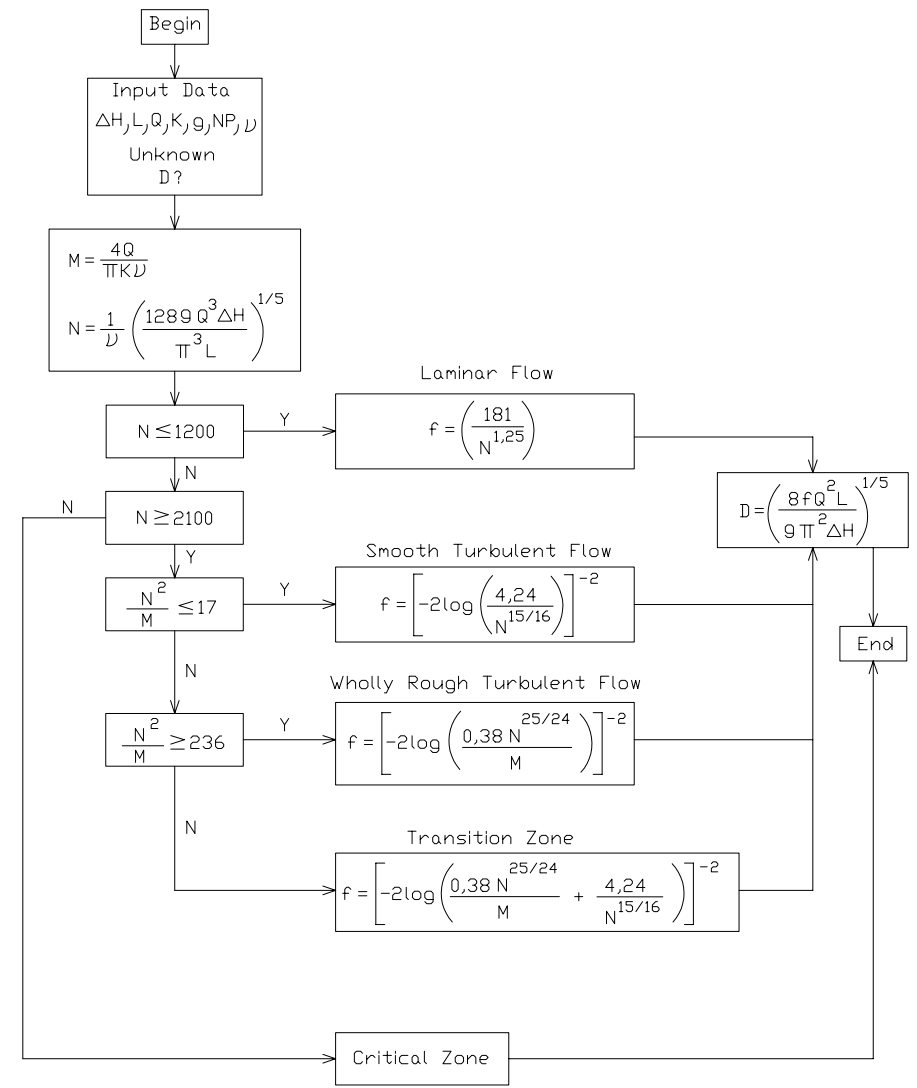

Figure 3: $\quad$ Block diagram for problem 3. 
To calculate the diameters in fig. 3 , it is proposed to use the following equation to calculate the friction factors for all flow regimes at Moody diagram, including the critical zone, instead of using the equations for " $\mathrm{f}$ " in fig. 3. It is important to note that the terms " $M$ " and " $N$ " are defined in fig. 3.

$$
f=\left\{\left(\frac{181}{N^{1,25}}\right)^{8}+9,5\left[\ln \left(\frac{0,38 N^{25 / 24}}{M}+\frac{4,24}{N^{15 / 16}}\right)-\left(\frac{1200}{N}\right)^{6}\right]^{-16}\right\}^{0,125}
$$

\subsection{Block diagram for problem 4}

The fourth formula is used to calculate the diameters of pipes given its lengths, head losses, absolute roughness, the kinematic viscosity of the fluid that flows in the pipes, the fluid velocities in the pipes and the gravity acceleration.

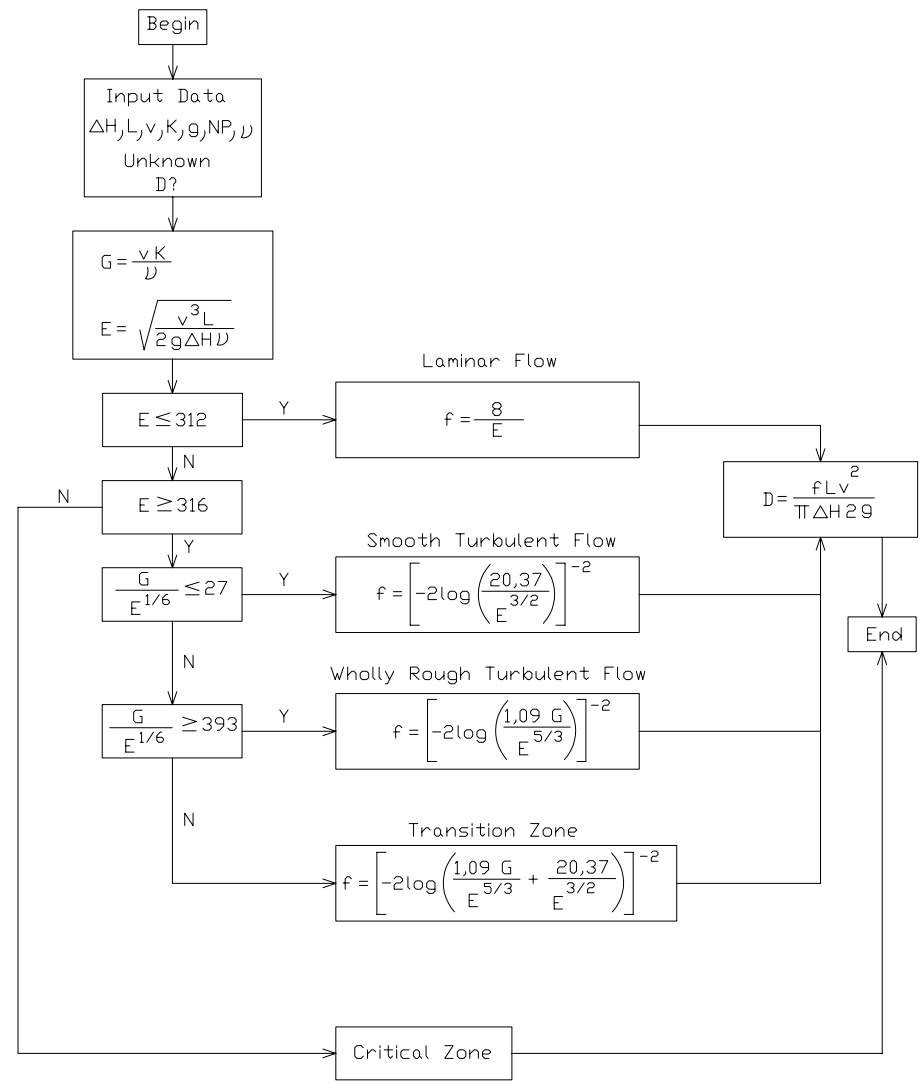

Figure 4: $\quad$ Block diagram for problem 4.

To calculate the diameters in fig. 4 , it is proposed to use the following equation to calculate the friction factors for all flow regimes at Moody diagram, 
including the critical zone, instead of using the equations for " $\mathrm{f}$ " in fig. 4 . It is important to note that the terms " $G$ " and " $E$ " are defined in fig. 4.

$$
f=\left\{\left(\frac{8}{E}\right)^{8}+9,5\left[\ln \left(\frac{1,09 G}{E^{5 / 3}}+\frac{20,37}{E^{3 / 2}}\right)-\left(\frac{312}{E}\right)^{6}\right]^{-16}\right\}^{0,125}
$$

\section{Case study}

The first and second formulae were used to calculate the steady state of a water main located at Jundiaí - SP - Brazil. This water main supplies water to five neighborhoods of Jundiaí (nodes 4, 6, 7, 9 and 10). The water main is composed of PVC pipes (1, 2, 3 and 5) and cast iron pipes (4, 6, 7, 8 and 9). The kinematic viscosity of the water was considered $10^{-6} \mathrm{~m}^{2} / \mathrm{s}$.

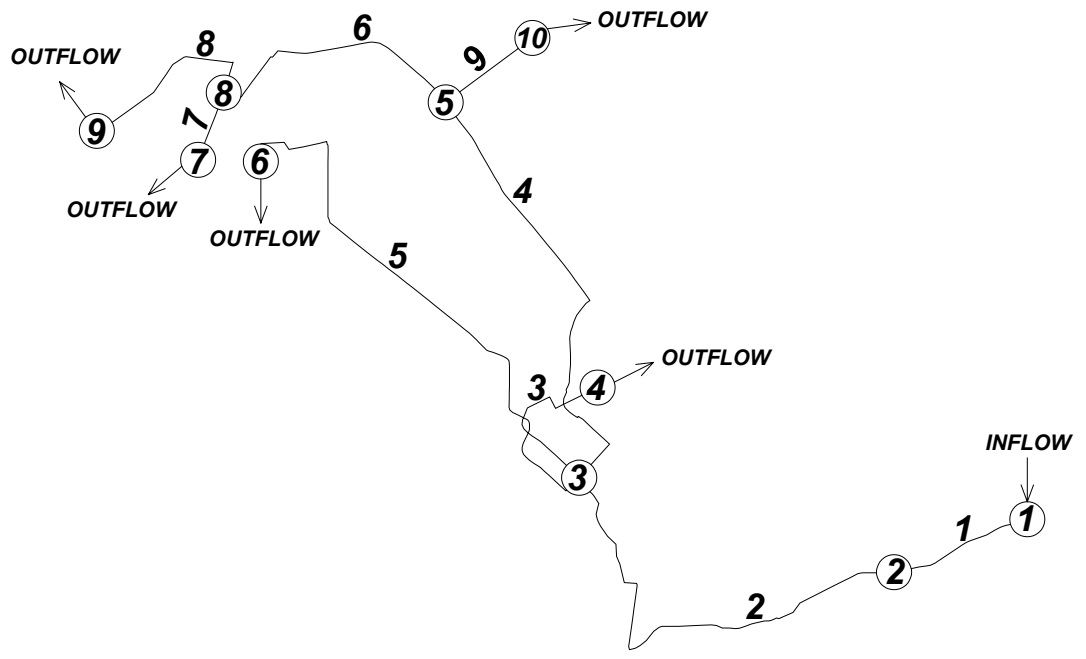

Figure 5: Water main scheme.

Table 1: $\quad$ Input data to calculate the discharges for the steady state.

\begin{tabular}{|c|c|c|c|c|}
\hline pipe & $\begin{array}{c}\text { diameter } \\
(\mathrm{m})\end{array}$ & $\begin{array}{c}\text { Length } \\
(\mathrm{m})\end{array}$ & $\begin{array}{c}\text { pipe absolute roughness } \\
(\mathrm{m})\end{array}$ & $\begin{array}{c}\text { calculated head losses } \\
(\mathrm{m})\end{array}$ \\
\hline 2 & 0,400 & 4728,181 & 0,0001 & 2,88400 \\
\hline 3 & 0,250 & 1252,575 & 0,0001 & 0,52408 \\
\hline 4 & 0,300 & 4107,069 & 0,00025 & 3,06983 \\
\hline 6 & 0,250 & 2501,266 & 0,00025 & 3,13298 \\
\hline 7 & 0,200 & 121,159 & 0,00025 & 0,37464 \\
\hline
\end{tabular}

The first formula to be used was the second one (eqn. (4)). To use eqn. (4), the head losses of the water main pipes had to be calculated. To calculate the 
head losses of the water main pipes, pressure gauges were installed for 5 days on nodes $1,2,3,4,5,6,7,8$ and 9 . Since pipe 9 is very small, a pressure gauge was not installed on node 10. After some mathematical operations, using an electronic spreadsheet, the head losses of pipes 2, 3, 4, 6 and 7 were calculated. The head losses were calculated based on the average pressure calculated from the pressures gauged in situ. Then software based on fig. 2 was developed to calculate the discharges in pipes 2, 3, 4, 6 and 7. The calculated discharges will be shown ahead. The head losses of pipes 1, 5, 8 and 9 were not calculated because the pressure gauge installed on node 1 did not work, the pressure gauge on node 6 was installed on a wrong place, the pressure gauge installed on node 9 did not work well and there was no pressure gauge on node 10 respectively. It is important to say that node 1 is an ordinary point of the water main. There is no reservoir, or pump, or valve etc. on it.

The first formula could be used by chance due to the problems on nodes 1,6 , 9 and 10 already commented. To use eqn. (3), the pressures on these nodes had to be calculated first. To calculate the pressures on these nodes, first, it was necessary to use the conservation of mass equation on nodes $2,3,5$ and 8 to calculate the discharges in pipes 1, 5, 8 and 9. Then software based on fig. 1 was developed to calculate the head losses of pipes 1, 5, 8 and 9. After some mathematical operations, the pressures on nodes 1, 6, 9 and 10 were calculated manually. The calculated head losses will be shown ahead.

Table 2: $\quad$ Input data to calculate the head losses for the steady state.

\begin{tabular}{|c|c|c|c|c|}
\hline pipe & diameter $(\mathrm{m})$ & length $(\mathrm{m})$ & pipe absolute roughness $(\mathrm{m})$ & calculated discharges $\left(\mathrm{m}^{3} / \mathrm{s}\right)$ \\
\hline 1 & 0,400 & 1419,043 & 0,0001 & 0,06609 \\
\hline 5 & 0,200 & 5292,597 & 0,0001 & 0,01821 \\
\hline 8 & 0,150 & 1673,930 & 0,00025 & 0,00301 \\
\hline 9 & 0,200 & 21,320 & 0,00025 & 0,00623 \\
\hline
\end{tabular}

To compare the results obtained by formulae 1 and 2, it was used a hydraulic network calculation program based on a non-elastic matrix model [12] to calculate the steady state of the water main. It was difficult to use this program because it was necessary to calculate the average water consumption of the five neighborhoods supplied by the water main and because the water department of Jundiaí does not have a reliable water leakage rate. So, after calculating and summing the average water consumption of each neighborhood, the calculated total average discharge was compared to the discharge in pipe 1 and a water loss rate of $57,51 \%$ for this region was found. To calculate the steady state, this water loss rate was included in the nodal demands of the water main. At first, this water loss rate was not reliable, because there was no proof yet that formula 1 was working well. Anyway, the hydraulic network calculation program was used. The input data for the hydraulic network calculation program, the results yielded by it and the results yielded by formulae 1 and 2 will be shown hereunder in tables 3 and 4 . 
Table 3: $\quad$ Input data for the water main for the steady state flow.

\begin{tabular}{|c|c|c|c|c|c|}
\hline node & nodal demand $\left(\mathrm{m}^{3} / \mathrm{s}\right)$ & node elevation $(\mathrm{m})$ & pipe & Length $(\mathrm{m})$ & Diameter $(\mathrm{m})$ \\
\hline 1 & -0.06609 & 706,617 & 1 & 1419,043 & 0,400 \\
\hline 2 & - & 718,580 & 2 & 4728,181 & 0,400 \\
\hline 3 & - & 710,091 & 3 & 1252,575 & 0,250 \\
\hline 4 & 0,01612 & 726,669 & 4 & 4107,069 & 0,300 \\
\hline 5 & - & 682,197 & 5 & 5292,597 & 0,200 \\
\hline 6 & 0,01614 & 713,265 & 6 & 2501,266 & 0,250 \\
\hline 7 & 0,02339 & 717,316 & 7 & 121,159 & 0,200 \\
\hline 8 & - & 710,415 & 8 & 1673,930 & 0,150 \\
\hline 9 & 0,00323 & 712,248 & 9 & 21,320 & 0,200 \\
\hline 10 & 0,00721 & 682,197 & & & \\
\hline
\end{tabular}

Table 4: Results for the steady state flow yielded by the hydraulic calculation program and formulae 1 and 2 .

\begin{tabular}{|c|c|c|c|c|c|c|c|}
\hline node & $\begin{array}{c}\text { hydraulic program } \\
\text { pressures } \\
(\mathrm{m})\end{array}$ & $\begin{array}{c}\text { average pressure } \\
\text { (gauged pressures) and } \\
\text { calculated pressures } \\
(\mathrm{m})\end{array}$ & pipe & $\begin{array}{c}\text { hydraulic } \\
\text { program } \\
\text { discharges } \\
\left(\mathrm{m}^{3} / \mathrm{s}\right)\end{array}$ & $\begin{array}{c}\text { formula 2 } \\
\text { discharges } \\
\left(\mathrm{m}^{3} / \mathrm{s}\right)\end{array}$ & $\begin{array}{c}\text { hydraulic program } \\
\text { head losses } \\
(\mathrm{m})\end{array}$ & $\begin{array}{c}\text { formula 1 } \\
\text { head } \\
\text { losses }(\mathrm{m})\end{array}$ \\
\hline 1 & 79,92 & 79,92 & 1 & 0,06609 & - & 0,86965 & 0.86959 \\
\hline 2 & 67,09 & 67,09 & 2 & 0,06609 & 0,06609 & 2,89762 & - \\
\hline 3 & 72,68 & 72,70 & 3 & 0,01612 & 0,01549 & 0,56682 & - \\
\hline 4 & 55,53 & 55,59 & 4 & 0,03383 & 0,03239 & 3,36397 & - \\
\hline 5 & 97,21 & 97,52 & 5 & 0,01614 & - & 7,25358 & 9.09611 \\
\hline 6 & 62,25 & 60,43 & 6 & 0,02662 & 0,02616 & 3,26739 & - \\
\hline 7 & 58,44 & 58,89 & 7 & 0,02339 & 0,02315 & 0,38552 & - \\
\hline 8 & 65,72 & 66,17 & 8 & 0,00323 & - & 0,53365 & 0.46836 \\
\hline 9 & 63,36 & 63,87 & 9 & 0,00721 & - & 0,00721 & 0,00549 \\
\hline 10 & 97,20 & 97,51 & & & & & \\
\hline
\end{tabular}

\section{Conclusions}

It is possible to conclude from tables 1, 2 and 4 that formulae 1 and 2 are working satisfactorily, because the results obtained by these formulae are close to the ones obtained by the hydraulic program used. It is also possible to conclude from the results in tables 1,2 and 4 that the calculated water loss rate $(57,51 \%)$ is reliable. Besides, the hydraulic program is reliable, because the results obtained by it, for any given hydraulic network, have already been compared to the results obtained by other hydraulic network calculation programs, like Epanet, calculating the same hydraulic network and the results of both programs are very close. The four formulae presented to calculate the friction factors have the advantage of being used to calculate the discharges, head losses and diameters of hydraulic networks without iterations. Since node 1 is an ordinary point of the water main, as already commented, the pressure on node 1 was possible to be calculated thanks to formula 1 and it was possible to use the hydraulic program also thanks to formula 1. Otherwise, it would have to be installed another pressure gauge on node 1 at least for another five days. Formulae 3 and 4 have not yet had the chance of being tested in a case study. Caution is recommended if one desires to use formulae 3 and 4.

\section{Symbol list}

$\{\Delta H\}$ head loss of the pipes in an any given hydraulic system (m)

$\{Q\}$ discharges in pipes in any given hydraulic system $\left(\mathrm{m}^{3} / \mathrm{s}\right)$ 
$\{D\} \quad$ pipe diameters in any given hydraulic system (m)

$\{N P\} \quad$ number of pipes in any given hydraulic system

$\{g\} \quad$ gravity acceleration $\left(\mathrm{m} / \mathrm{s}^{2}\right)$

$\{0\} \quad$ kinematic viscosity of the fluid in any given hydraulic system $\left(\mathrm{m}^{2} / \mathrm{s}\right)$

$\{K\} \quad$ absolute roughness of the pipes in any given hydraulic system $(\mathrm{m})$

$\{L\} \quad$ pipe lengths in any given hydraulic system (m)

$\{f\} \quad$ friction factor of the pipes in any given hydraulic system (m)

$\{R e\} \quad$ Reynolds number defined in fig. (1)

$\{a\}$ numerical constraint of Konakov's formula

$\{b\} \quad$ numerical constraint of Konakov's formula

$\{v\} \quad$ fluid velocity in pipes in any given hydraulic system $(\mathrm{m} / \mathrm{s})$.

\section{References}

[1] Equações explícitas para o fator de atrito de Darcy-Weisbach, http://pt.wikipedia.org/wiki/Equa\%C3\%A7\%C3\%B5es_expl\%C3\%ADcita s_para_o_fator_de_atrito_de_Darcy-Weisbach

[2] Lima, $\overline{\text { L. }}$ F. M., Termo de atrito em escoamento transitório para condutos forçados, http://www.teses.usp.br/teses/disponiveis/3/3147/tde-16052006$161003 /$

[3] Kamand, F. Z., Hydraulic friction factors for pipe flow. Journal of Irrigation and Drainage Engineering, 114(2), pp. 311-323, 1988.

[4] Von Bernuth, R. D. \& Wilson, T., Friction factors for small diameter plastic pipes. Journal of Hydraulic Engineering, 115(2), pp. 183-192, 1989.

[5] Sonnad, J. R. \& Goudar, C. T., Constraints for using Lambert W functionbased explicit Colebrook-White equation. Journal of Hydraulic Engineering, 130(9), pp. 929-931, 2004.

[6] McKeon, B. J., Zagarola, M. V. \& Smits, A. J., A new friction factor relationship for fully developed pipe flow. Journal of Fluid Mechanics, 538, pp. 429-443, 2005.

[7] Yoo, D. H. \& Singh, V. P., Two methods for the computation of commercial pipe friction factors. Journal of Hydraulic Engineering, 131(8), pp. 694-704, 2005.

[8] Sonnad, J. R. \& Goudar, C. T., Turbulent flow friction factor calculation using a mathematically exact alternative to the Colebrook-White equation. Journal of Hydraulic Engineering, 132(8), pp. 863-867, 2006.

[9] Cheng, N., Formulas for friction factor in transitional regimes. Journal of Hydraulic Engineering, 134(9), pp. 1357-1362, 2008.

[10] Nekrasov, B., Hidráulica, $2^{\circ}$ edition, Editorial Mir: Moscú, pp. 95, 1966

[11] Souza, P. A., Nova Formulação Explícita para o Cálculo do Fator de Atrito (f) de Escoamento Forçado. Anais do XII Congresso Latinoamericano de Hidráulica, São Paulo, pp. 75-85, 1986.

[12] Diniz, V. E. M. G., Souza, P. A. \& Luvizotto Jr, E., Non-Elastic matrix model for hydraulic networks calculation. Water resources Management $I V$, eds. C. A. Brebbia \& A. G. Kungolos, WIT Press, pp. 111-121, 2007. 